\title{
INTERCOMPARISON OF DESIS, SENTINEL-2 (MSI) AND SENTINEL-3 (OLCI) DATA FOR WATER COLOUR APPLICATIONS
}

\author{
M. A. Soppa ${ }^{1 *}$, D. A. $\operatorname{Dinh}^{2}$, B. Silva ${ }^{3}$, F. Steinmetz ${ }^{4}$ L. Alvarado ${ }^{1}$, A. Bracher ${ }^{1,5}$ \\ ${ }^{1}$ Alfred Wegener Institute Helmholtz Centre for Polar and Marine Research, Bremerhaven, Germany - msoppa@ awi.de, \\ leonardo.alvarado@awi.de, astrid.bracher@awi.de \\ ${ }^{2}$ Alfred Wegener Institute Helmholtz Centre for Polar and Marine Research, Helgoland, Germany - dinhdieuanh1319@gmail.com \\ ${ }^{3}$ German Federation for Biological Data, Bremen, Germany - bsilva@gfbio.de \\ ${ }^{4}$ HYGEOS, Euratechnologies, Lille, France - fs@hygeos.com \\ ${ }^{5}$ Institute of Environmental Physics, University of Bremen, Bremen, Germany
}

\section{Commission I, WG I/1}

KEY WORDS: hyperspectral, multispectral, atmospheric correction, inland waters, coastal waters.

\begin{abstract}
:
In this work, we investigate the potential of DESIS hyperspectral data for water colour applications as preparation for the exploitation of data from the future EnMAP mission. We show results on the intercomparison of Level 2 data of the DESIS sensor, Sentinel-2 MultiSpectral Instrument (S2-MSI) and Sentinel-3 Ocean and Land Colour Instrument (S3-OLCI) processed with the Polymer atmospheric correction. Examples of mapping of water quality parameters in inland and coastal waters is provided for different ecosystems (e.g. lagoon, clear lakes, estuaries). First results of Polymer applied to DESIS data at different study regions show similar spatial distribution of chlorophyll-a concentration (Chl-a) to S2-MSI and S3-OLCI.
\end{abstract}

\section{INTRODUCTION}

Hyperspectral imaging for water applications has gained force in the last years with the launch of new hyperspectral missions as DESIS and PRISMA and with the upcoming EnMAP and PACE missions (Giargino et al. 2020, Dierssen et al. 2021). The hyperspectral data combined with high spatial resolution opens new chances to explore water colour satellite data and develop new products for inland and coastal regions. An example of this potential synergistic use of data from the different sensors is presented in Figure 1, when at the same day there were overflights of DESIS, S2B and S3B sensors at Lake Constance. DESIS has the strength of the high spectral and spatial resolution; S2-MSI has a better temporal resolution than DESIS combined with high spatial resolution. On the other hand, S3-OLCI provides the most suitable data for water colour applications of all three sensors in terms of signal-to-noise ratio and temporal coverage.

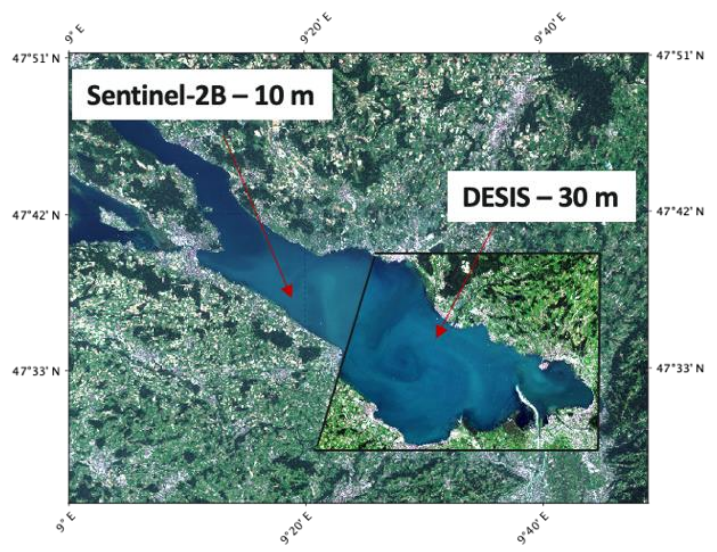

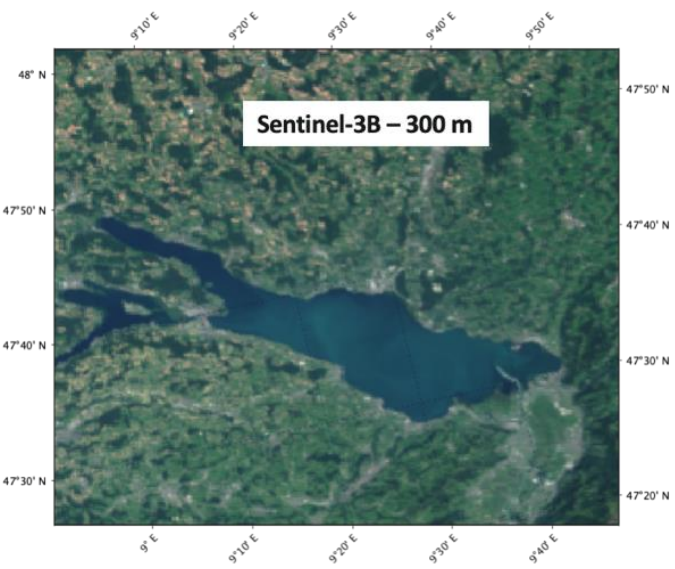

Figure 1. Lake Constance true colour composites of Level 1 (R:665, G:560, B:490) on 08 August 2021: top - Sentinel 2BMSI overlayed with DESIS, bottom - Sentinel-3B-OLCI.

Dekker and Pinnel (2018) revised the requirements for a sensor to capture the optical complexity of inland and coastal aquatic environments: e.g. wavelength range from 360 to $1000 \mathrm{~nm}, 5 \mathrm{~nm}$ spectral sampling and full width half maximum, high signal-tonoise ratio, spatial resolution of about $17-33 \mathrm{~m}$ and temporal resolution as high as possible. However, as a dedicated sensor for these often optically complex waters is still to come, we need to explore the synergy between the available sensors. It is necessary to understand how the different sensors perform to combine the strengths and advantages of individual instruments.

Probably one of the most challenging steps of processing satellite data for water colour application is the atmospheric correction (AC) (Frouin et al. 2019, Dierssen et al. 2021). The AC algorithms are applied to remove atmospheric/surface/bottom effects from the radiance measured by the sensors at the top of the atmosphere. The remaining water signal is the main 
information used in the algorithms and only a small percentage of the total signal measured by the sensor. For this reason, the quality of the satellite derived products depends partially on the AC.

Nowadays there are several AC algorithms based in different methods, but few algorithms that are free for scientific used and that can be applied to different sensors (e.g. Polymer - Steinmetz et al. 2011, hyperspectral L2gen - Ibrahim et al. 2008, Acolite Vanhellemont and Ruddick, 2018); a requirement if we are looking for the synergy of Level 2 products. In this work, we present preliminary results of the evaluation of Polymer AC algorithm applied to data from DESIS. In addition, we applied Polymer to S2-MSI and S3-OLCI to intercompare with DESIS retrievals.

Polymer is a spectral matching algorithm in which atmospheric and oceanic signals are obtained simultaneously using the fully available spectrum. The algorithm is available as a python package and has been largely applied to ocean colour sensors. A recent evaluation of Polymer applied to data from the Hyperspectral Imager for the Coastal Ocean (HICO) showed good performance of Polymer over coastal waters (Soppa et al. 2021), thus supporting its application in DESIS data.

\section{METHODS}

The dataset comprises satellite data acquired over Lake Constance and seven other study regions with AERosol RObotic NETwork - Ocean Colour (AERONET-OC) stations: Airike, Galata, Green Bay, Lucinda, Socheongcho, Thornton and Venice Bay (Figure 2). DESIS Level 1B data at $2.55 \mathrm{~nm}$ spectral resolution were downloaded from EOWEB GeoPortal. Level 1C MSI and Level 1B OLCI data were downloaded from the Copernicus Open Access Hub. Level 2 data were obtained after applying the Polymer (v. 4.13, Steinmetz et al. 2011) to Level 1 data of all three sensors. Remote sensing reflectance (Rrs) was calculated by dividing the normalized water leaving reflectance (output of Polymer) by pi.

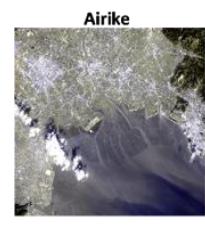

Thorton

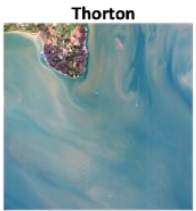

Figure 2. True colour composites of DESIS Level 1B for the eight investigated regions. the station in more open water, but the chlorophyl-a retrieval inside the bay is likely affected by the bottom reflectance. The spikes in the spectra could be reduced by binning the data, which could also improve the stripping effect.

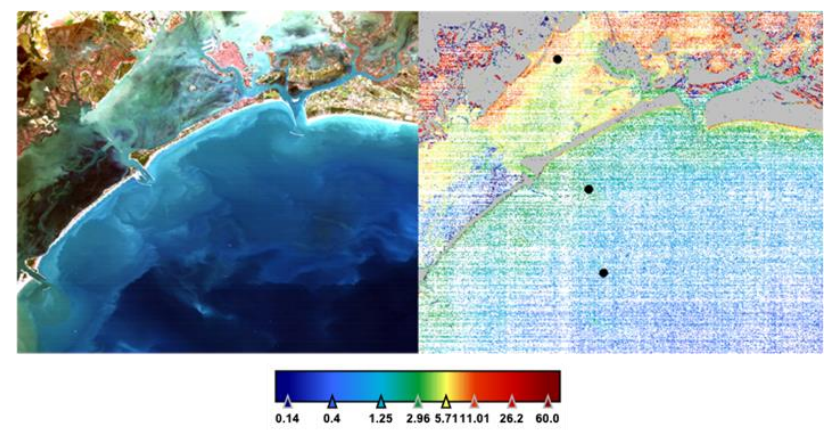

Figure 3. True colour composite of Level 1B DESIS (04.10.2018, left) and the retrieved chlorophyll-a concentration $\left(\mathrm{mg} / \mathrm{m}^{3}\right)$ with Polymer at Venice Bay. Colorbar indicates chlorophyll-a concentration in $\mathrm{mg} / \mathrm{m}^{3}$ and the black circles the position of the Rrs spectrum shown in Figure 4. Grey and white regions are masked by applying Polymer flags: optimized parameters are out of bounds, thick aerosol, cloud, land, high air mass.

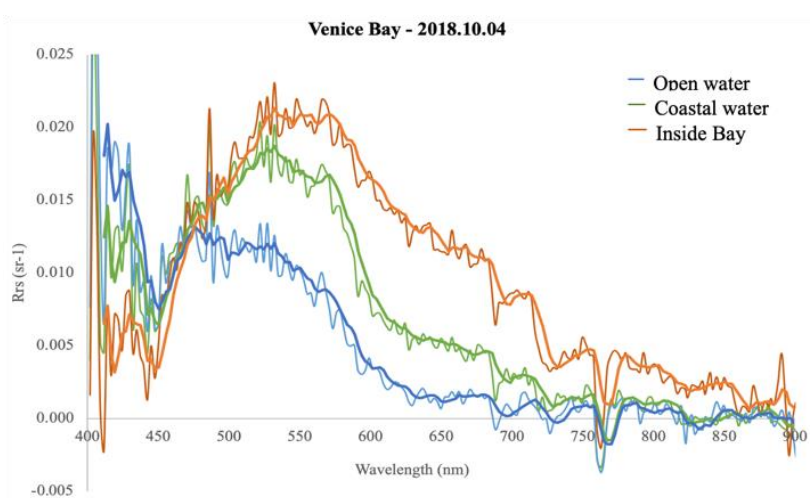

Figure 4. Rrs spectrum for the three stations plotted in Figure 3. Solid lines represent spectra smoothed by a 5-point moving average.

Another important result is the improvement of the flagging by Polymer when applied to hyperspectral data. For example, at the Airike region (Figure 5), as area of shallow and turbid waters, the tidal flats are flagged by the inconsistency flag in the DESIS data, but not in the S2-MSI. In the S2-MSI image the pixels were flagged as case-2 waters only. According to Steinmetz et al. (2016), the inconsistency flag is raised when, at any band the water of atmospheric reflectance exceeds the total reflectance. Here as well, the chlorophyll-a retrieval is likely influenced by the high sediment loads and shallow bathymetry, and should be interpreted with caution.

\section{RESULTS}

The results showed strong stripping effect on the Polymer Level 2 retrievals (Figure 3 ), however, this issue could be minimized using Level 1C data instead of Level 1B. Nevertheless, the DESIS chlorophyll-a products at the Venice Bay for a scene acquired in 04.10.2018 showed consistent spatial distribution and concentration (Figure 3). The spectral comparison of open waters, coastal waters and waters inside the bay reflects the expected spectral variability of these three water types (Figure 4). The stations at the coast and inside the bay show higher reflectance due to increased particle concentration compared to 
DESIS - 04.02.2019

S2-MSI - 01.02.2019

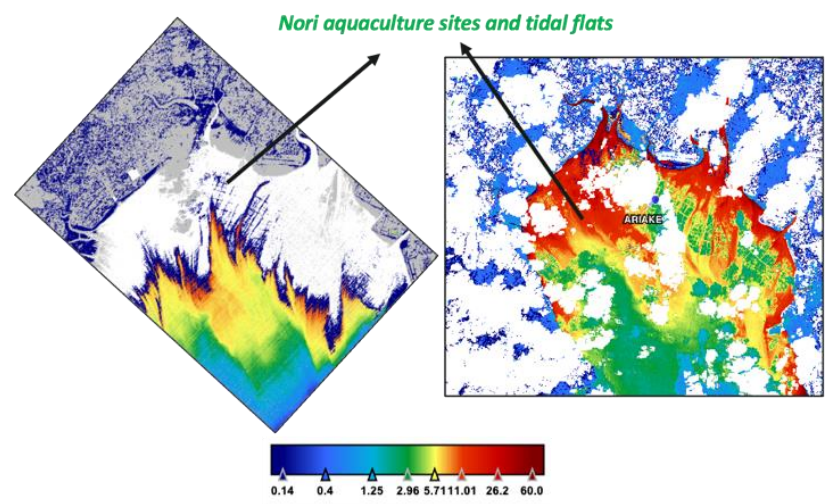

Figure 5. Comparison of DESIS (left) and S2-MSI (right) derived chlorophyll-a concentration at Airike. The pin on the S2 image shows the position of the AERONET-OC station and the colorbar indicates chlorophyll-a concentration in $\mathrm{mg} / \mathrm{m}^{3}$.

DESIS data acquired at Galata region in 13.02.2020 showed the potential of the sensor to observe coccolithophore blooms (Figure 6). The spectrum of the bloom shows relatively higher values with respect to spectrum out of the bloom (Figure 7), and Rrs in the same magnitude of AERONET-OC Rrs during a coccolithophore event in 2020 (Cazzaniga et al., 2021).

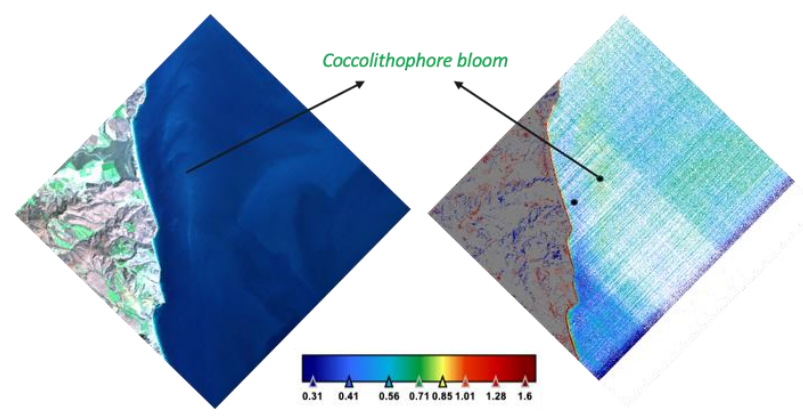

Figure 6. True colour composite of DESIS Level (left) and the retrieved chlorophyll-a concentration $\left(\mathrm{mg} / \mathrm{m}^{3}\right)$ with Polymer at the Galata AERONET-OC study region in 13.02.2020. Grey and white regions are masked as in Figure 3. Black dots indicate the position of the normalized water leaving reflectance spectrum shown in Figure 7.

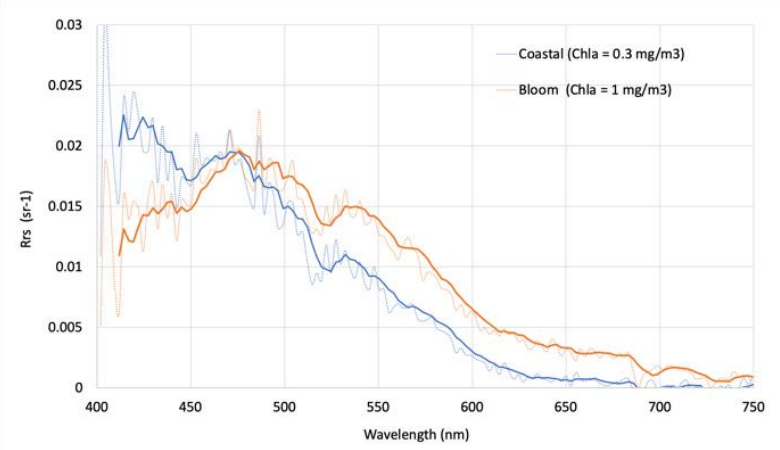

Figure 7. Rrs spectrum for the two stations plotted in Figure 6. Solid lines represent spectra smoothed by a 5 -point moving average.

At Lucinda study region the total suspended matter (TSM) maps of DESIS and S2 showed similar distribution and magnitude (Figure 8). The TSM was derived using a simple empirical algorithm based on Rrs 665 (Riddick et al., 2019), originally tuned for Vigo region in Spain.
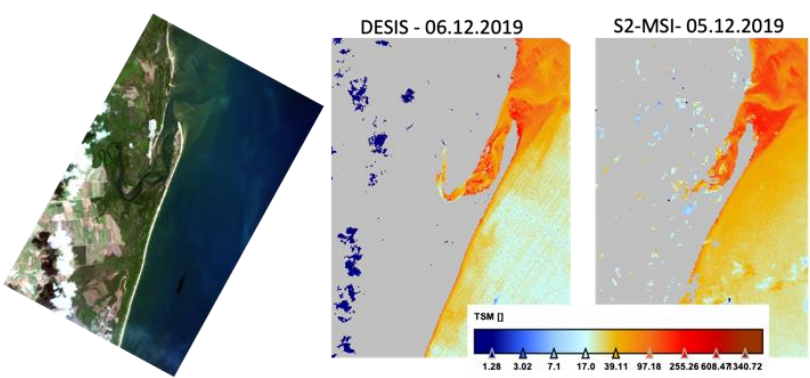

Figure 8. True colour composite of DESIS Level 1B (left) and the retrieved total suspended matter $(\mathrm{mg} / \mathrm{L})$ with Polymer at the Lucinda AERONET-OC study region. Grey and white regions are masked as in Figure 3.

Looking at the Polymer derived chlorophyll-a concentration maps of DESIS and S2-MSI in 25.12.2019 at Lucinda area, the larger differences in the retrievals were observed in the region marked by the circle in Figure 9. Although no in situ measurements are available, the results indicate that hyperspectral information from DESIS allows to account for the optically complexity of the region than the multispectral information from S2-MSI.

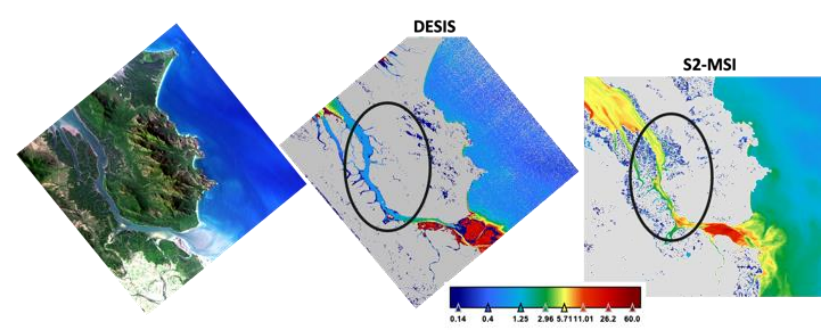

Figure 9. True colour composite of DESIS Level 1 (left) and the retrieved chlorophyll-a concentration $\left(\mathrm{mg} / \mathrm{m}^{3}\right)$ with Polymer at the Lucinda AERONET-OC study region for DESIS and S2MSI in 25.12.2019. Grey and white regions are masked as in Figure 3.

A quick comparison of the Rrs spectra of DESIS and S2-B reveled larger differences at the blue bands (443 and $490 \mathrm{~nm}$ ) and better agreement at the station in "ocean" than in the "channel" (Figure 10).
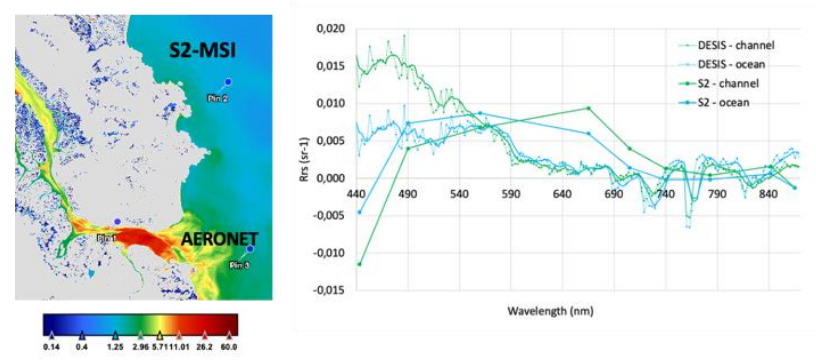

Figure 10. Left: S2-MSI retrieved chlorophyll-a concentration $\left(\mathrm{mg} / \mathrm{m}^{3}\right)$. Right: Rrs spectrum for pin 2 (ocean) and pin 1 (channel). Pin 3 shows the position of the AERONET-OC station. Solid lines represent spectra smoothed by a 5-point moving average. 


\section{CONCLUSION}

The results showed consistent retrievals of DESIS products using Polymer atmospheric correction algorithm and good agreement between Polymer-DESIS and Polymer-S2-MSI products. We observed that more pixels are flagged correctly by Polymer using DESIS data and that the hyperspectral information also helps to account for the optical complexity of the studied environments than S2-MSI. DESIS-Polymer retrievals will be improved by: replacing DESIS L1B data by L1C, binning data before applying the AC, avoiding the $<430 \mathrm{~nm}$ due to manufacturing defects, testing different band settings. The validation against in situ AERONET-OC data will be performed in a future study when we process DESIS L1C data, that provides better geolocation. However, a quick look at the available in situ and satellite data showed very few match-ups. We reinforce the need of support for field campaigns and development of autonomous technologies for providing continuous in situ hyperspectral data as for example WATERHYPERNET (Vansteenwegen et al., 2019) and WISPstation network (Bresciani et al., 2020).

\section{ACKNOWLEDGEMENTS}

This investigation was supported by the Federal Ministry of Economics and Technology (BMWi) and DLR grants 50EE1923 within the EnMAP scientific preparation program, and 50EE1915 within the project TypSynSat (Monitoring the Phytoplankton Functional Types by Synergistic Exploitation of Multi- and Hyperspectral Satellite Observations). DLR and Teledyne are acknowledged for DESIS level 1 satellite data. ESA is acknowledged for Sentinel-2 and Sentinel-3 Level 1 data.

\section{REFERENCES}

Bresciani, M., Pinardi, M., Free, G., Luciani, G., Ghebrehiwot, S., Laanen, M., Peters, S., Della Bella, V., Padula, R., Giardino, C., 2020. The Use of Multisource Optical Sensors to Study Phytoplankton Spatio-Temporal Variation in a Shallow Turbid Lake. Water, 12, 284.

Cazzaniga, I., Zibordi, G., Mélin, F., 2021. Spectral variations of the remote sensing reflectance during coccolithophore blooms in the Western Black Sea. Remote Sensing of Environment, 264, 112607.

Dekker, A.G., Pinnel, N. Feasibility Study for an Aquatic Ecosystem Earth Observing System; Committee on Earth Observation Satellites (CEOS) and Commonwealth Scientific and Industrial Research Organization: Canberra, Australia, 2018.

Dierssen, H.M., S. Ackleson, K. Joyce, E. Hestir, A. Castagna, S. Lavender, and M. McManus, 2021. Living up to the Hype of Hyperspectral Aquatic Remote Sensing: Science, Resources and Outlook. Frontiers in Environmental Science. 9, 134.

Frouin, R. J., Franz, B. A., Ibrahim, A., Knobelspiesse, K., Ahmad, Z., Cairns, B., et al., 2019. Atmospheric Correction of Satellite Ocean-Color Imagery during the PACE Era. Frontiers in Earth Sciences, 7, 145.

Giardino, C., Bresciani, M., Braga, F., Fabbretto, A., Ghirardi, N., Pepe, M., et al., 2020. First Evaluation of PRISMA Level 1 Data for Water Applications. Sensors, 20.

Ibrahim, A., Franz, B., Ahmad, Z., Healy, R., Knobelspiesse, K., Gao, B.C., Proctor, C., Zhai, P.W., 2018. Atmospheric correction for hyperspectral ocean color retrieval with application to the
Hyperspectral Imager for the Coastal Ocean (HICO). Remote Sensing of Environment, 204, 60-75.

Riddick, C., Wang, S., Spyrakos, E., Hunter, P., Tyler, A., Braga, F., Brando, V., Scarpa, G., Zoffoli, L., Gernez, P., Barille, A-L., Barille, L., Harin, N., Gonzalez Vilas, L., Torres Palenzuela, J., van der Hiele, T., Peters, S., 2019. D3.10 Validation Report. CoastObs Project.

Soppa, M. A., Silva, B., Steinmetz, F., Keith, D., Scheffler, D., Bohn, N., Bracher, A., 2021. Assessment of Polymer Atmospheric Correction Algorithm for Hyperspectral Remote Sensing Imagery over Coastal Waters. Sensors, 21(12), 4125.

Steinmetz, F., Deschamps, P. Y., Ramon, D., 2011. Atmospheric correction in presence of sun glint: Application to MERIS. Optics Express, 19, 9783-9800.

Steinmetz, F., Ramon, D., Deschamps, P, Y., 2016. ATBD v1 Polymer atmospheric correction algorithm, D2.3, OC-CCI project, cci.org/?q=webfm_send/658 http://www.esa-oceancolour-

Vanhellemont, Q., Ruddick, K., 2018. Atmospheric correction of metre-scale optical satellite data for inland and coastal water applications. Remote Sensing of Environment, 16, 586-597.

Vansteenwegen, D., Ruddick, K., Cattrijsse, A., Vanhellemont, Q., Beck, M., 2019. The Pan-and-Tilt Hyperspectral Radiometer System (PANTHYR) for Autonomous Satellite Validation Measurements-Prototype Design and Testing. Remote Sensing, 11,1360 . 